\title{
Analysis of Failure of Dynamic Hip Screw Fixation in the Management of Intertrochanteric Fractures in the Elderly
}

\author{
ASHRAF M.M. RASHAD, M.Sc.*; ALI M. EMRAN, M.D.**; OSAMA A. SELEEM, M.D.** and \\ MOSTAFA H. HEGAZY, M.D.** \\ The Department of Otorhinolaryngology, Tanta University Hospital* and The Department of Orthopedic Surgery, \\ Faculty of Medicine, Tanta University**
}

\begin{abstract}
Background: Intertrochanteric femoral fractures are common in elderly patients. If they are not adequately treated, they may cause a considerable change in the quality of life. The goal of operative treatment is strong and stable fixation of the fracture fragments in which the Dynamic Hip Screw (DHS) serves as the standard and is the most common device for fixation of intertrochanteric femoral fracture.
\end{abstract}

Aim of Study: To analyze failure of Dynamic Hip Screw fixation in treatment of simple intertrochanteric fracture femur in the elderly.

Study Design and Setting: A prospective and retrospective randomized clinical trial in a tertiary care center.

Patients and Methods: This study was carried out on 50 patients with simple intertrochantric fracture femur fixed by Dynamic Hip Screw assessed clinically by Hip Harris Score (HHS) and radiologically by Tip Apex Distance (TAD), Lag screw position in femoral neck, changes occurred in fracture position and healing of the fracture.

Results: There was highly statistically significant changes of proximal femoral morphology leading to unsatisfactory results of clinical Hip Harris Score (HHA).

Conclusion: The Dynamic Hip Screw (DHS) device is the implant of choice in stable intertrochanteric fractures, and Restoration of normal proximal femur morphology give the best clinical results of DHS in fixation of intertrochanteric fractures.

Key Words: Intertrochanteric femur - Dynamic Hip ScrewHip Harris Score - Tip Apex Distance.

\section{Introduction}

INTERTROCHANTERIC femoral fractures are common in elderly patients. If they are not ade-

Correspondence to: Dr. Ashraf M.M. Rashad,

The Department of Demonstrator of Otorhinolaryngology, Tanta University Hospital quately treated, they may cause a considerable change in the quality of life. The trauma becomes more severe, and leads to worsening of existing disease, which is the major cause of mortality from this fracture [1].

Various treatment modalities have been introduced for the reduction and fixation of intertrochanteric fractures, including Dynamic Hip Screw (DHS), Proximal Femoral Nail, Trochanteric Fixation Nail (TFN), External Fixator and Bipolar Hemi-arthroplasty. All of which have their specific advantages and disadvantages [2].

The application of the contemporary operational methods substantially reduces the mortality risks, in comparison to the conservative methods of treatment [3].

The goal of operative treatment is strong and stable fixation of the fracture fragments in which the Dynamic Hip Screw (DHS) serves as the standard and is the most common device for fixation of intertrochanteric femoral fracture $[4,5]$.

Failure usually occurs with loss of fixation of the lag screw with resultant varus Angulations and medial collapse at the fracture site, plate pull-off from the shaft, implant disassembly, or fatigue failure in cases of delayed union [4-7].

The Tip Apex Index (TAD) could be a good predictor of failure of fixation. The tip apex index (TAD) is the sum of the distance from the tip of the screw to the apex of the femoral head on anterior-posterior view and lateral views. It should be between 20 and $25 \mathrm{~mm}[8]$. 


\section{Patients and Methods}

This study was retrospective and prospective randomized clinical study carried out on 50 patients admitted to Orthopedic Department of Tanta University Hospitals. The source of the retrospective portion of the study was the clinical database available in Orthopedic Department of Tanta University Hospitals in the period from December 2010 to November 2015. The prospective patients were operated in the Orthopedic Department in Tanta University Hospitals in the period from December 2015 to December 2016.

There were 55 patients in this study, 2 patients died with non-related causes and 3 patients lost during follow-up.

A written informed consent was obtained from all patients or their caregivers, all data of patients was confidential with secret codes and private file for each patient, all given data was used for the current medical research only and the study was carried out in accordance with the Declaration of Helsinki [9] and the principles of good clinical practice. Study protocol was approved by Institutional Ethical Committee on July 2016 by issue number 3 03 10/07/15.

In this study there were 50 patients with intertrochanteric fractures of femur 37 were females and 13 were males all of them were above 60 years old ranged from 60:75 years old we categorize them in 3 main groups: Group (I) from 60:65 years old 18 were females and 7 were males, Group (II) from 66:70 years old 12 were females and 4 were males, and Group (III) from 71:75 years old 7 were females and 2 were males. 29 patients (58\%) were in the right side and 21 patients (42) were in the left side.

In this study mechanisms of injury were simple fall in most of cases (34 patients), fall on stairs (12 patients) and Road Traffic Accident (RTA) in 4 patients. According to medical status 10 patients didn't have other medical problems, 21 patients had Hypertension (HTN), 3 patients had Diabetes Mellitus (D.M) with Hypertension (HTN), 6 patients had Diabetes Mellitus (D.M), 4 patients were cardiac and 6 patients was cardiac hypertensive.

According to occupation, there were 11 farmers, 13 housewives, 5 teachers, 8 workers, 3 engineers, 2 accountants, 2 electricians, 2 businessmen, 1 plumber, 1 coach, 1 hairdresser and 1 tailor.

According to Hajbaghery et al., [10] (EQ-5D) used to evaluate Quality of Life (QOL) and activity of patients before trauma and after surgery there were 24 active patients with average score 81 , 26 inactive patients with average score 34 and 55\% of the patients returned to their previous activities after surgery. And fracture type in this study according to AO classification was 28 cases were 31-A1 (56\%), 22 cases were 31-A2.

\section{Methods:}

Skin traction for the fractured limb was done to stabilize the fracture, reduce pain and preserve the limb length and to relax and reduce muscle spasm which acts around the fracture. This is applied as a temporary measure together with analgesics. Time lag before surgery was 5 days till improvement of their general condition and after physician and anesthesia consultation.

Care was given to the skin at the fracture site, back of the patient, bowel and bladder functions "retention or incontinence" and chest exercises.

\section{Surgical procedures:}

Systemic broad spectrum antibiotic, namely a third generation cephalosporin, is begun an hour before the operation and continued for a week postoperatively on 12-hours intervals. Anesthesia was chosen according to the patient's condition, operations were performed under spinal anesthesia in 34 patients and under general anesthesia in 16 patients.

Closed reduction of the fracture is performed by gentle traction, abduction, slight external rotation and adduction then the foot is fastened to the foot plate and enough traction is applied to restore length and normal neck shaft angle. The classical approach is a straight lateral incision, splitting the ilio-tibial tract, and gently elevating the vastus lateralis muscle which may be splited or elevated and the fracture was fixed by the standard Dynamic Hip Screw (DHS).

\section{Ambulation:}

Partial weight bearing started on 2 weeks after discharge in 26 cases using crutches while partial weight bearing started within 4 weeks in 15 cases. Partial weight bearing was delayed until after the 6 weeks in 9 cases, because the patients were osteoporotic and the implants were unstable. Patients had been followed-up every 2 weeks by clinical data and radiological evaluation.

In this study clinical and radiological evaluation was done after 6 months and data were collected to analyze that DHS fixation in simple intertro- 
chanteric fracture of femur in the elderly will fail or not.

\section{Clinical assessment:}

The Harris Hip Score (HHS) [11] used to assess hip function more specifically.

\section{Total harris hip score:}

- Excellent=90-100 points.

- Good=80-89 points.

- Fair=70-79 points.

- Poor $<70$ points.

\section{Radiological assessment:}

\section{1- Evaluation of fixation and implant position:}

A- Tip Apex Distance (TAD): This measurement, expressed in millimeters, is the sum of the distances from the tip of the lag screw to the apex of the femoral head on both the Anteroposterior (AP) and lateral radiographic views The sum should be $<25 \mathrm{~mm}$ average from $(19 \mathrm{~mm}: 25 \mathrm{~mm})$ to minimize the risk of lag screw cutout.

$B$ - Lag screw position in femoral neck: To provide the TAD lower than $25 \mathrm{~mm}$, the lag screw should be placed centrally as far as possible. Although peripheral placement increases the tip-apex distance, it is not always related with cut-out failure.

\section{2- Evaluation of bone implant interaction:}

$A$ - Changes in the lag screw position in femoral neck: Femoral neck shaft angle ranging from $120^{\circ}$ to $135^{\circ}$, above $135^{\circ}$ it becomes coxa valga, and less than $120^{\circ}$ it is called coxa vara changes of lag screw in femoral neck may occurred due to loosening of lag screw in femoral neck or screw cut out.

B- Changes occurred in the fracture position: Varus collapse $8^{\circ}$ occurred due to reduction in neck shaft-angle less than contralateral the proximal fragment fell into varus due to superior lag screw in the neck or early full weight bearing. Valgus collapse occurred and the proximal fragment was fell into valgus due to excessive neck-shaft angle compared with the contralateral side and inferior lag screw in the neck. Radiographs were done in every visit analysis for collapse at the fracture site and changes in the neck-shaft angle was performed by comparing radiographs at different stages of fracture healing.

3- Healing of the fracture: Mal-union may be into valgus or varus and this depend mainly on position of lag screw in femoral neck. Inferior lag screw in the neck lead to valgus mal-union and lengthening and superior lag screw lead to varus mal-union and shortening (leg length discrepancy) delayed union may be due to bad general condition of the patient, osteoporosis and infection of the surgical site.

4- Changes in proximal femur morphology:

- Femoral Neck Width (FNW).

- Femoral Neck Length (FNL).

- Femoral Axis Length (FAL).

- Neck-Shaft Angle (NSA).

- Great Trochanter-Pubic Symphysis Distance (GTPSD).

The choice of these measurement indexes based on Pires et al., [12] studies of morphometric analysis of the proximal region of the femur, changes of both sides were compared by students' $t$-test [13] to (non-significant, mild or significant) the proximal part of the contralateral femur was used as a control for the measurements. The measurements were taken and changes were recorded.

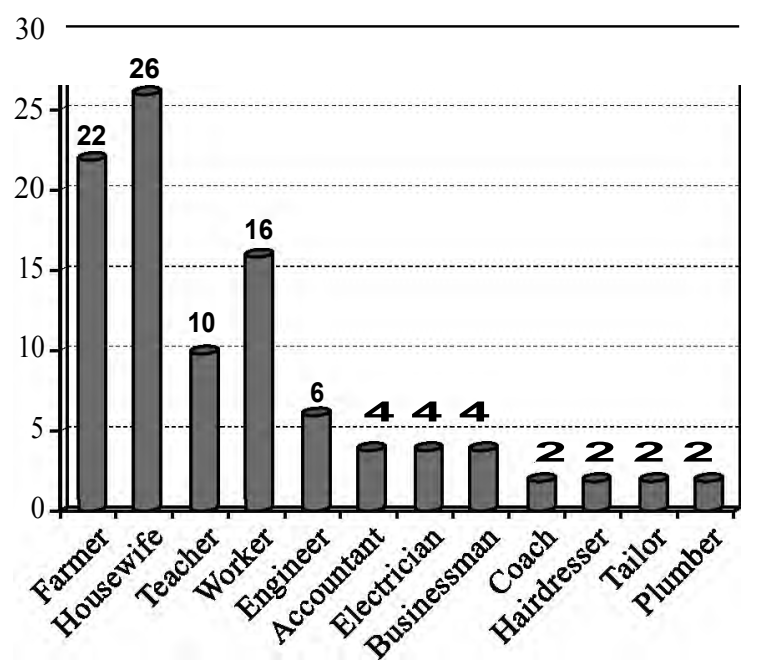

Fig. (1): Distribution of patients' occupation.

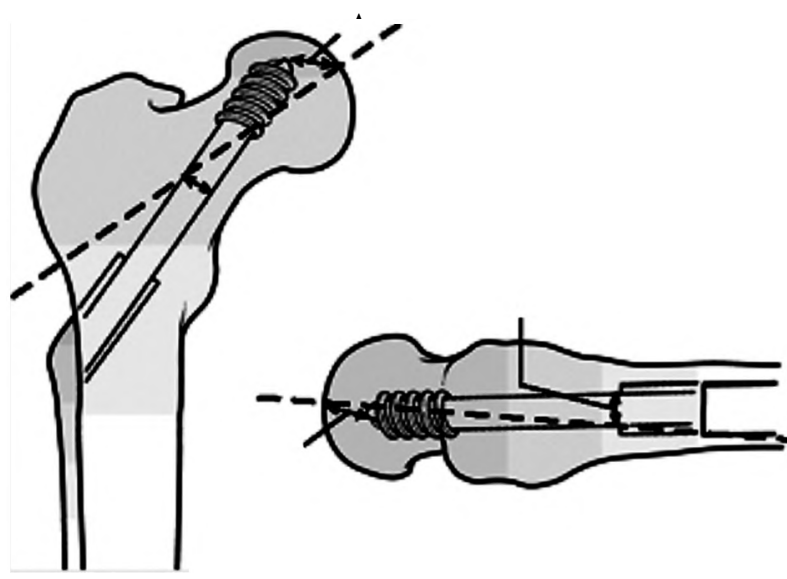

Fig. (2): The Tip-Apex Distance (TAD). 
Table (1): Harris hip score [11] .

\begin{tabular}{|c|c|}
\hline Harris hip score & \\
\hline $\begin{array}{l}\text { Pain (check one): } \\
\text { - None or ignores it. } \\
\text { - Slight, occasional, no compromise in activities. } \\
\text { - Mild pain, no effect on average activities, rarely moderate } \\
\text { pain (30) with unusual activity; may take aspirin. } \\
\text { - Moderate pain, tolerable but makes concession to pain. } \\
\text { Some limitation of ordinary activity or work. May require } \\
\text { occasional pain medication stronger than aspirin. } \\
\text { - Marked pain, serious limitation of activities. } \\
\text { - Totally disabled, crippled, pain in bed, bedridden. }\end{array}$ & $\begin{array}{l}(44) \\
(40) \\
(30) \\
(20)\end{array}$ \\
\hline $\begin{array}{l}\text { Limp: } \\
\text { - None. } \\
\text { - Slight. } \\
\text { - Moderate. } \\
\text { - Severe. }\end{array}$ & $\begin{array}{l}(11) \\
(8) \\
(5) \\
(0)\end{array}$ \\
\hline $\begin{array}{l}\text { Support: } \\
\text { - None. } \\
\text { - Cane for long walks. } \\
\text { - Cane most of time. } \\
\text { - One crutch. } \\
\text { - Two canes. } \\
\text { - Two crutches or not able to walk. }\end{array}$ & $\begin{array}{l}(11) \\
(7) \\
(5) \\
(3) \\
(2) \\
(0)\end{array}$ \\
\hline $\begin{array}{l}\text { Distance walked: } \\
\text { - Unlimited. } \\
\text { - Six blocks. } \\
\text { - Two or three blocks. } \\
\text { - Indoors only. } \\
\text { - Bed and chair only. }\end{array}$ & $\begin{array}{l}(11) \\
(8) \\
(5) \\
(2) \\
(0)\end{array}$ \\
\hline $\begin{array}{l}\text { Sitting: } \\
\text { - Comfortably in ordinary chair for one hour. } \\
\text { - On a high chair for } 30 \text { minutes. } \\
\text { - Unable to sit comfortably in any chair. }\end{array}$ & $\begin{array}{l}(5) \\
(3) \\
(0)\end{array}$ \\
\hline $\begin{array}{l}\text { Enter public transportation: } \\
\text { - Yes. } \\
\text { - No. }\end{array}$ & $\begin{array}{l}(1) \\
(0)\end{array}$ \\
\hline $\begin{array}{l}\text { Stairs: } \\
\text { - Normally without using a railing. } \\
\text { - Normally using a railing. } \\
\text { - In any manner. } \\
\text { - Unable to do stairs. }\end{array}$ & $\begin{array}{l}(4) \\
(2) \\
(1) \\
(0)\end{array}$ \\
\hline $\begin{array}{l}\text { Put on shoes and socks: } \\
\text { - With ease. } \\
\text { - With difficulty. } \\
\text { - Unable. }\end{array}$ & $\begin{array}{l}(4) \\
(2) \\
(0)\end{array}$ \\
\hline $\begin{array}{l}\text { Absence of deformity: (All yes }=4 \text {; less than } 4=0 \text { ) } \\
\text { - Less than } 30^{\circ} \text { fixed flexion contracture. } \\
\text { - Less than } 10^{\circ} \text { fixed abduction. } \\
\text { - Less than } 10^{\circ} \text { fixed internal rotation in extension. } \\
\text { - Limb length discrepancy less than } 3.2 \mathrm{~cm} .\end{array}$ & $\begin{array}{l}\text { Yes No } \\
\text { Yes No } \\
\text { Yes No } \\
\text { Yes No }\end{array}$ \\
\hline $\begin{array}{l}\text { Range of motion }(* \text { indicates normal }) \text { : } \\
\text { - Flexion }\left(* 140^{\circ}\right) \text {. } \\
\text { - Abduction }\left(* 40^{\circ}\right) \text {. } \\
\text { - Adduction }\left(* 40^{\circ}\right) \\
\text { - External rotation }\left(* 40^{\circ}\right) \text {. } \\
\text { - Internal rotation }\left(* 40^{\circ}\right) \text {. }\end{array}$ & $\begin{array}{l}- \\
- \\
- \\
- \\
-\end{array}$ \\
\hline $\begin{array}{l}\text { Range of motion scale: } \\
\quad-211^{\circ}-300^{\circ} \\
-161^{\circ}-210^{\circ} \\
-101^{\circ}-160^{\circ} \\
-61^{\circ}-100^{\circ} \\
-31^{\circ}-60^{\circ} \\
-0^{\circ}-30^{\circ}\end{array}$ & $\begin{array}{l}(5) \\
(4) \\
(3) \\
(2) \\
(1) \\
(0)\end{array}$ \\
\hline Range of motion score & - \\
\hline
\end{tabular}

Total harris hip score
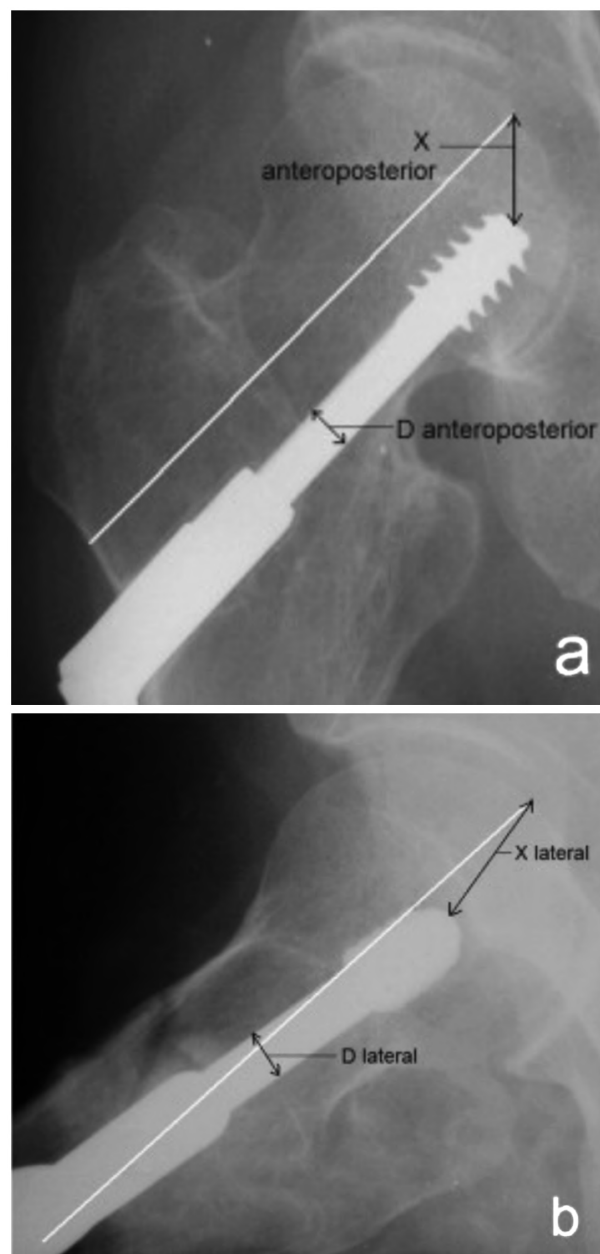

Fig. (3): Measurement of the distance between the tip of the lag screw to the apex of the femoral head (X) and the diameter of the lag screw (D) on the (A) Anteroposterior and (B) Lateral radiographs.

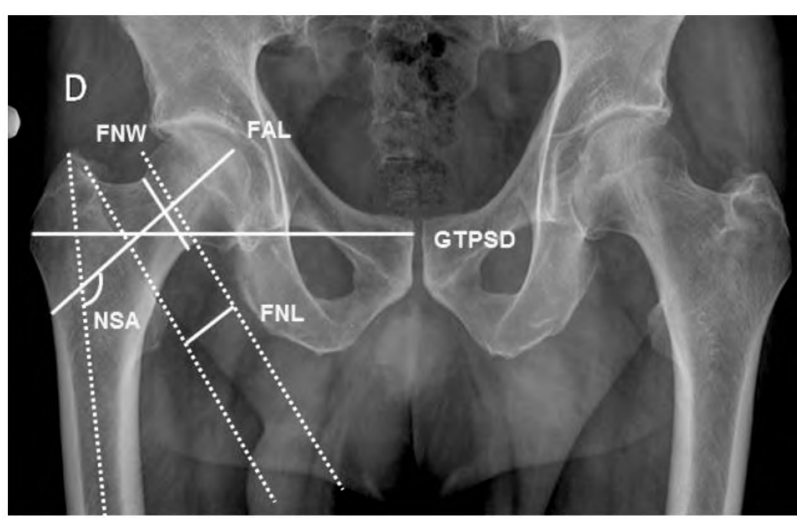

Fig. (4): The analyzed measurements of proximal femur morphology.

Table (2): The parameters of proximal femur morphology.

\begin{tabular}{lll}
\hline Femoral neck width & FNW & $18.5-35 \mathrm{~mm}$ \\
Femoral neck length & FNL & $26-35 \mathrm{~mm}$ \\
Femoral axis length & FAL & $100-110 \mathrm{~mm}$ \\
Neck-shaft angle & NSA & $126-139 \mathrm{~mm}$ \\
Great trochanter-pubic symphysis distance & GTPSD & $160-170 \mathrm{~mm}$ \\
\hline
\end{tabular}




\section{Results}

A combined prospective and retrospective study of 50 patients with intertrochanteric fractures. They were evaluated both radiologically and clinically.

\section{Clinical assessment:}

In this study, according to Harris Hip Scoring system (HHS), there were 13 patients with excellent score with average score 92, 21 patients with good score with average score 83,14 patients with fair score with average score 75 and 2 patients with poor score with average score 67 . Patients with excellent and good score are satisfactory and others with fair and poor score are un-satisfactory, $p$ value 0.922 not significant.

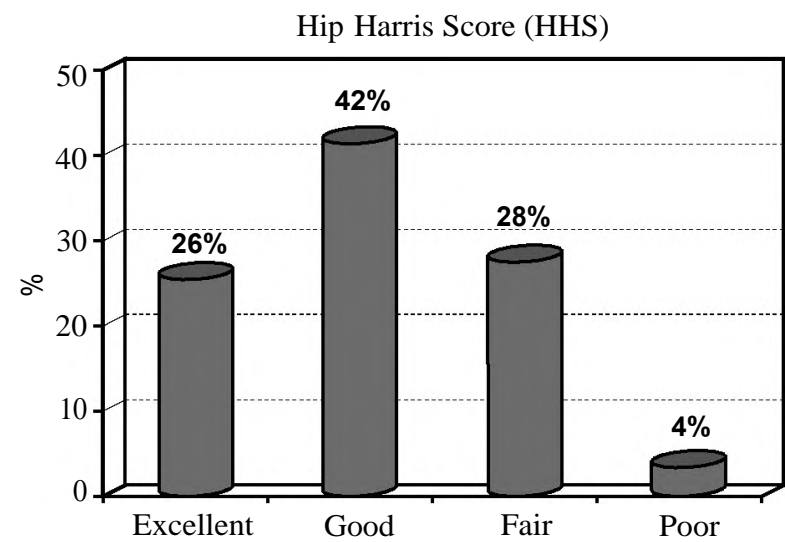

Fig. (5): Distribution of results according to Hip Harris Score.

\section{Radiological assessment:}

1- Evaluation of fixation and Implant position:

A- Tip Apex Distance (TAD): In this study Tip Apex Distance (TAD) was below $25 \mathrm{~mm}$ in 27 cases, $25-30 \mathrm{~mm}$ in 14 cases and above $30 \mathrm{~mm}$ in 9 cases.

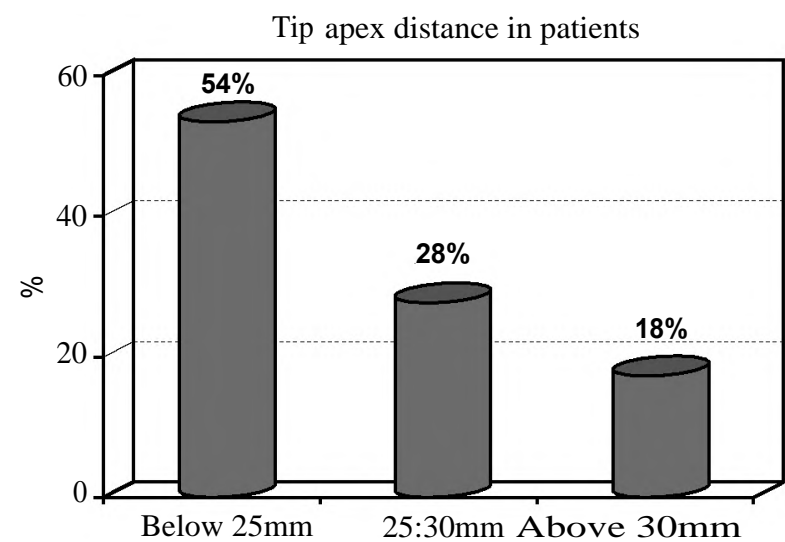

Fig. (6): Distributive analysis of Tip Apex Distance (TAD).

B- Lag screw position in femoral neck: Lag screw position in femoral neck was central in 31 cases, inferior in 18 cases with valgus angulation and superior in 1 case that had varus angulation.

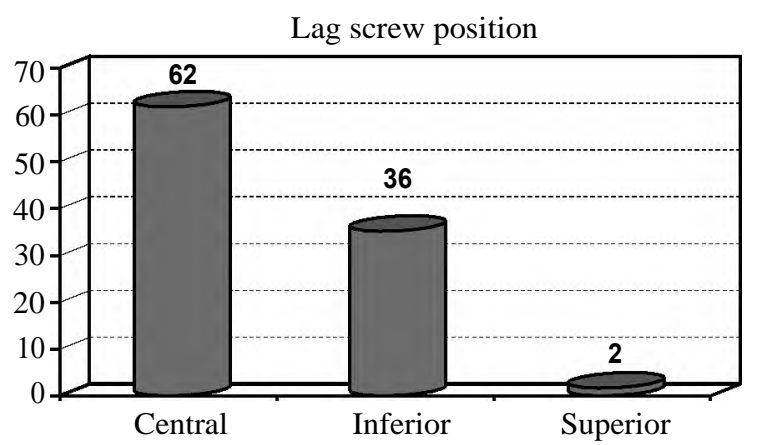

Fig. (7): Distributive analysis lag screw position in femoral neck.

\section{2- Evaluation of bone implant interaction:}

A- Changes in the lag screw position in femoral neck: 9 cases had changes in position of lag screw due to infection that lead to loosening, 2 cases had avascular necrosis of the head of femur, 4 case had lag screw pulled out, one of them case had separation between lag screw and side plate.

\section{B- Changes occurred in the fracture position:}

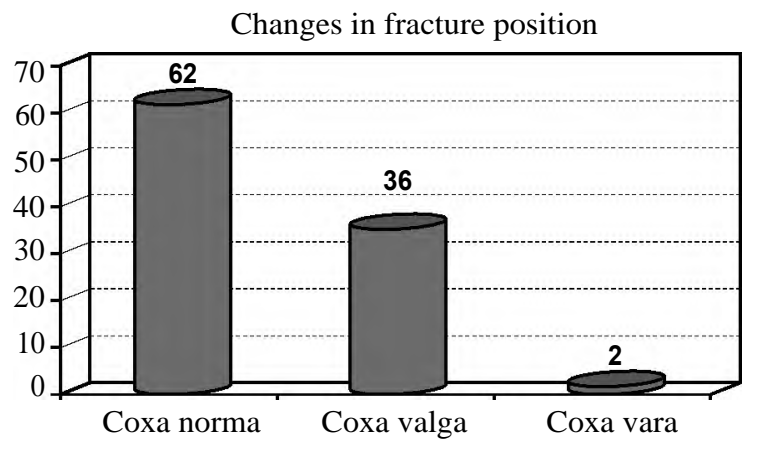

Fig. (8): Distribution of changes of fracture position.

\section{3- Healing of the fracture:}

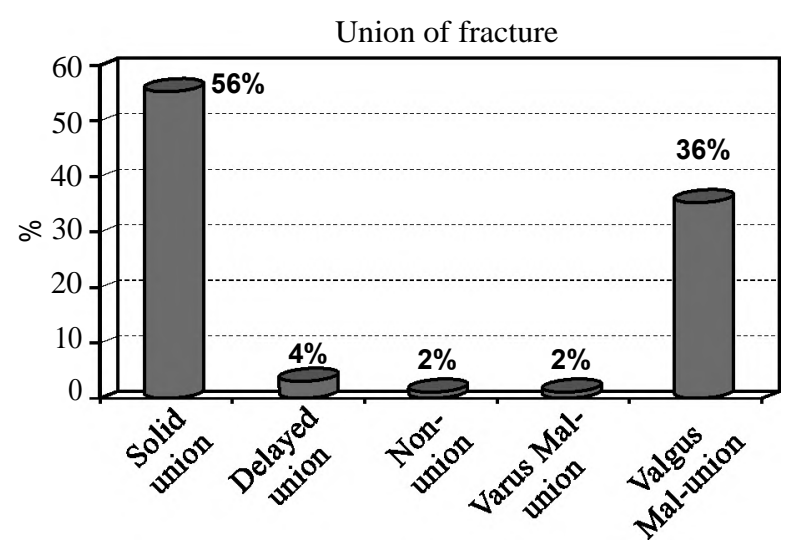

Fig. (9): Distribution of bone healing of intertrochanteric fractures. 


\section{4- Changes in proximal femur morphology:}

Table (3): Statistical analysis of mean between proximal femoral sides.

\begin{tabular}{|c|c|c|c|c|c|}
\hline Parameters & $\mathbf{N}$ & $\begin{array}{c}\text { DHS hips } \\
(\text { mean } \pm \text { SD) }\end{array}$ & $\begin{array}{c}\text { Contralateral } \\
\text { hips } \\
(\text { mean } \pm \mathrm{SD})\end{array}$ & Changes & $\begin{array}{c}t \text {-test } \\
(p \text {-value })\end{array}$ \\
\hline $\begin{array}{l}\text { - Femoral } \\
\text { Neck Width } \\
\text { (FNW) }\end{array}$ & 50 & $29.0 \pm 0.6$ & $29.5 \pm 0.5$ & -0.5 & 0.001 \\
\hline $\begin{array}{l}\text { - Femoral } \\
\text { Neck } \\
\text { Length } \\
\text { (FNL) }\end{array}$ & 50 & $13.2 \pm 0.5$ & $13.5 \pm 0.3$ & -0.3 & 0.001 \\
\hline $\begin{array}{l}\text { - Femoral } \\
\text { Axis Length } \\
\text { (FAL) }\end{array}$ & 50 & $68.3 \pm 1.7$ & $72.7 \pm 0.4$ & -4.4 & 0.001 \\
\hline $\begin{array}{l}\text { - Neck Shaft } \\
\text { Angle } \\
\text { (NSA) }\end{array}$ & 50 & $135.6 \pm 5.2$ & $127.70 \pm 2.6$ & 7.9 & 0.001 \\
\hline $\begin{array}{l}\text { - Great } \\
\text { Trochanter- } \\
\text { Pubic } \\
\text { Symphysis } \\
\text { Distance } \\
\text { (GTPSD) }\end{array}$ & 50 & $109.9 \pm 0.5$ & $113.1 \pm 0.3$ & -3.5 & 0.001 \\
\hline
\end{tabular}

In relationship between Hip Harris Score and patient age, mode of trauma, pre-existing medical disease, patient quality of life, changes occurred at fracture site, proximal femoral changes and fracture healing $p$-value was significant and it was found that $p$-value was significant 0.00122 for simple fall, $p$-value was significant 0.002378 as inactive cases had unsatisfactory Hip Harris Score, $p$-value was significant 0.00099 as highly significant changes of proximal femoral morphology leading to unsatisfactory results of Hip Harris Score and $p$-value was significant 0.004906 as mal-union, delayed union and non-union had unsatisfactory Hip Harris Score.

In relationship between Hip Harris Score and fracture side, fracture type, Tip Apex Distance and Lag screw position of femoral head $p$-value was not significant.

\section{Discussion}

Dynamic fixation devices including the dynamic hip screw has afforded significant advances in the treatment of intertrochanteric fractures. Wolfgang et al., [14] have concluded that a dynamic device is the implant of choice for stable intertrochanteric fractures. In this study the idea, the aim is to analyze the causes of Dynamic Hip Screw (DHS) failure in management of intertrochanteric fracture of the femur in the elderly. The stability of the construct depends upon the strength of the lag screw in the proximal fragment. Leung et al., [15] recommended that the lag screw be placed in the inferior half of the head and neck in the frontal view and centrally in the lateral view. Boriani et al., [16] reported that the lag screw must always be inserted in the lower portion of the femoral head. This was in agreement without findings that the lag screw did not cut out when placed posterior and inferior close to the medial neck border. It was found that the position of the lag screw was more important determining factor because cases fixed with acceptable alignment, have shown no cut out or migration and went on to union when an anterior or posterior position was avoided. Birdle et al., [17] reported a lower incidence of screw cut out and/or migration compared to previous series, reflecting the good lag screw position which they obtained. They found that the incidence of central positioning of the lag screw in the femoral neck was higher for the DHS [17].

Goffin et al., [18] studies focused on the position of the lag screw and assessed the range of positions that are usually reported in large clinical studies to only two positions, that is, middle and inferior middle positions DHS, in superior position increased the risk of the device cutting out of the femoral head or Varus angulation of the proximal fragment increases the lever arm on the fixation since it makes the femoral neck more horizontal and therefore functionally longer when body weight is applied. In this study there were 31 patients with lag screw in central position had good union, 25 of them had satisfactory Hip Harris Score 80\% (11 excellent and 14 good score) so central lag screw position play an important role in success of fixation of intertrochanteric fractures by Dynamic Hip Screw. In this study there were 18 patients with inferior position had valgus mal-union, 9 of them had satisfactory Hip Harris Score (2 excellent and 7 good) and 9 had unsatisfactory Hip Harris Score ( 8 fair and 1 poor), so inferior position of lag screw may be accepted to some degree of valgus mal union and in extreme valgus lead to limb lengthening and limping which may affect walking and daily activities of patients that affect clinical score of Hip Harris score. In this study there was 1 patient with superior lag screw had varus malunion,so varus mal-union is not accepted at all and lead to limb shortening associated with limping, abductor muscle insufficiency, hip pain, and back pain.

Regarding the position of the tip-apex distance of the lag screw, Baumgaertner et al., [19] reported that central and deep screw placement gives optimal fixation and that Tip Apex Distance TAD less than $25 \mathrm{~mm}$ resulted in fewer failures. The DHS lag screw occupies about $55 \%$ of the total crosssectional area of the femoral neck. Thus, with the 
DHS, a significantly greater proportion of cancellous bone is removed, which could have adverse consequences particularly in small femoral necks. However, despite the greater volume of bone displaced by the load-bearing shaft of the screw, yet the increased diameter of lag screw had resulted in a greater resistance to cut-out Hayens et al., [20] In this study Tip Apex Distance below 25mm was found in 27, 21 of them had satisfactory Hip Harris Score (9 excellent and 12 good score) Tip Apex Distance (TAD) was $25-30 \mathrm{~mm}$ in 14 cases in these cases partial weight bearing started after 3 weeks and full weight bearing after 6 weeks and Tip Apex Distance was above $30 \mathrm{~mm}$ was found in 9 cases, 4 of them had screw cut out so delayed weight bearing was done in 5 cases started after 6 weeks, so Tip Apex Distance play an important role to prevent DHS cut out or failure.

The average neck-shaft angle in this study ( $\mathrm{n}=$ 50) was $136.6^{\circ}$ (range $128^{\circ}$ to $142^{\circ}$ ). In this study the results are almost similar to that of Siwach, Isaac and Toogood et al., but differs largely from that of Saikia et al. The mean femoral neck length in this study is $13.5 \mathrm{mms}$ whereas Siwach observed maximum effective neck length as $37.2 \mathrm{mms}$ and minimum effective neck length as $22.6 \mathrm{mms}$. The mean neck width in this study was $29 \mathrm{mms}$ which was less when compared with the observations of Siwach who had observed it as $31.8 \mathrm{~mm}$. Hoaglund 21 in his comparative study on the anatomy of proximal femur, found significant differences in the measurements of the head, neck, and proximal femoral shaft of average normal Caucasians and Hong Kong chinese people. According to him the average neck-shaft angle of caucasians is $135^{\circ}$ and anteversion angle is $8^{\circ}$. Kate found the Formosans to have lowest average neck shaft-angle $\left(125.6^{\circ}\right)$ and Andamanians the highest angle $\left(134^{\circ}\right)$. He also found a difference in the angle between various races of India. He found the largest angle $\left(133^{\circ}\right)$ from Madurai (South India) and the smallest average angle $\left(122^{\circ}\right)$ from Bombay. Saikia [22] has observed variations of neck-shaft angle between the North Eastern population Mongoloids and Caucasians. It was considered the Egyptians population in this study the average angles $\left(136.6^{\circ}\right)$ almost same as previous studies Chauhan et al., [23] concluded that the variations in the parameters of the proximal femur and acetabulum were insignificant among the different populations in India but the data of two different countries (race) varied significantly. Thus it is clear that the proximal femoral geometry varies among different ethnic groups. Therefore usage of implants designed exclusively for Western bones will not be suitable for other ethnic groups. A comparison between the dimensions found in Ravichandran et al., [24] study and the dimensions of DHS implants shows that this implant is oversized for the Indian skeleton and sufficient bone stock is not available for an effective fixation. Use of such implant doesn't affect the functional end result of surgery and achieves purpose of internal fixation and an early rehabilitation. In this study, the results showed compatibility between dimensions of DHS and Egyptian femora.

The Dynamic Hip Screw (DHS) is the implant of choice for stable trochanteric fractures higher angle implants (eg. DHS barrel angle: $150^{\circ}$ ) causes mal-union in valgus thus altering the biomechanics both at hip and knee joint posing the patients to a greater risk of secondary arthritis $[25,26]$. Insertion of this screw needs reaming thus removing the available cancellous bone. Screws with large thread diameter occupy greater area in the neck and head of the femur. Such a large area drilled in the neck of femur takes away viable cancellous bone. To quote an example, the thread diameter of the DHS is $12.5 \mathrm{~mm}$ and barrel diameter is $12.6 \mathrm{~mm}$. Insertion of this screw needs reaming up to $11.5 \mathrm{~mm}$ (i.e. $1.15 \mathrm{~cm}$ ) and tapping up to $13.5 \mathrm{~mm}$ (i.e. $1.35 \mathrm{~cm}$ ). This removes a large cancellous bone stock cylinder from the neck. Siwach had observed the neck width as $31.8 \mathrm{~mm}$. The width of the neck in this study is only $29 \mathrm{~mm}$. Therefore it is clear that this implant is suitable for Egyptian femora, but if it didn't reach to good reduction or get a proper position of lag screw in the neck, it would occupy most of the available space in the neck and would cause tamponade effect resulting in non-union and avascular necrosis. Mishra et al., [27] in their study on a second look at rational of implant design for the proximal femur have concluded that the Western implants should be used only after careful consideration of preoperative planning. He also stresses that the fracture implant designs should be specific for different races bones.

Pires et al., [12] measured the parameter of proximal femur and compared the normal hips measurement with the fractured hips by using students' $t$-test and found the following results [13] The median of the femoral axis length for the patients aged up to 30 years was $118 \mathrm{~mm}$; for the patients aged from 31 to 65 years it was $111 \mathrm{~mm}$ and for the patients aged 66 years or over it was $112 \mathrm{~mm}$. This difference was statistically significant, Pires concluded that the differences are between and among age group "up to 30 years" and " 31 to 65 years", "and up to 30 years" and "66 years or over", while the patients from the "up to 30 years" have a statistically higher median than the patients 
from the "31 to 65 years", and higher than the patients from the "66 years or over" (4). In this study it was $68.4 \mathrm{~mm}$ in age group from 60 to 65 years and was $67.7 \mathrm{~mm}$ in "66 to 70 years" and was $68.8 \mathrm{~mm}$ in "71 to 75 ", this difference was statistically non-significant in measurements after fixation.

The median of the Neck-Shaft Angle (NSA) for the patients aged up to 30 years was $132^{\circ}$; for the patients aged from 31 to 65 years it was $129^{\circ}$ and for the patients aged 66 years or over it was $129^{\circ}$. This difference was statistically significant, Pires concluded that the differences are between and among the group "up to 30 years" and " 31 to 65 years" and "up to 30 years" and "66 years or over", while the patients from the "up to 30 years" have a statistically higher median than the patients from the " 31 to 65 years", and higher than the patients from the "66 years or over" [12].

In this study it was $133.9^{\circ}$ in age group from 60 to 65 years and was $136.4^{\circ}$ in "66 to 70 years" and was $138.8^{\circ}$ in "71 to $75^{\prime \prime}$ this difference was statistically significant in measurements after fixation. Statistically significant difference was detected in the median of the Femoral Neck Length (FNL) in keeping with the fracture. For the nonfractured femurs, the median of this variable was equal to $36 \mathrm{~mm}$ and for the fractured femurs it was equal to $33 \mathrm{~mm}$. At this point, the normality of the femoral neck length was verified according to sex, and was not normal for the male sex.

In this study the $t$-test used to compare the changes of measurements of proximal femur after fixation and contralateral side and there were 10 patients (20\%) non-significant changes, 11 patients (22\%) significant and 29 patient (58\%) highly significant changes. Unlike other studies, measurements of the neck-shaft angle based on the axis of the proximal femur, and evaluated varus and valgus mal-union and found the relation between changes in proximal femur morphology and its clinical effect on patients and found that restoration of normal proximal femur morphology after fixation of intertrochanteric fractures by DHS gave us better clinical results same as Ravichandran et al., [24] .

Statistically significant difference was also detected in the femoral neck length between the sexes. It was concluded that the median of the femoral neck length for men is statistically higher than the median of the women. Due to the results obtained, comparisons were made between the femoral neck length of the men and of the women, separately, according to the occurrence of fracture. The mean femoral neck length variable was com- pared among the women, and the median among the men. No statistically significant difference was detected in the femoral neck length according to the occurrence of fracture. For the femoral neck length variable, it was concluded that sex was a "confusing factor", as it influenced the size of the femoral neck length with statistically significant difference in relation to the fracture, when not considered in the analysis. In performing the comparison of this variable according to the occurrence of fracture separately for each sex, this difference did not appear significant [12]. In this study after fixation changes were significant different according to sex as males were less changed than females because osteoporosis is higher in females.

It was found that 10 patients with nonsignificant changes in proximal femur morphology; all of them were excellent in clinical score in HHS. Eleven patients with significant changes in proximal femur morphology ( 3 were excellent, 6 were good and 2 were fair) in HHS. Twenty nine patients with highly significant changes in proximal femur 15 of them were good, 12 were fair, and 2 were poor in HHS.

In this study there is correlation between clinical and radiological changes of intertrochanteric fractures fixed by Dynamic Hip Screw as highly significant changes of proximal femoral morphology had low Hip Harris Score.

Regarding the Quality of Life (QOL) of patients after surgery, Hajbaghery et al., [10] reported that the chance of undesirable quality of life in patients with a history of hip fracture surgery was 9.17 times greater than the elderly without a similar history and patients without previous hip surgery had lower pain, discomfort, anxiety, depression, health status, self-care, and level of activity than other patients with the history of hip fracture. The mean scores of quality of life were also significantly lower in patients with a history of hip fracture surgery regardless of all demographic variables such as age, sex, living arrangements, income, marriage, level of education, and job so therefore, developing supportive systems and rehabilitation facilities may improve patients' quality of life [9] In this study, QOL and activity of patients evaluated before trauma and there were $48 \%$ active patient and $52 \%$ inactive, $55 \%$ of the patients returned to their previous activity and QOL after surgery and rehabilitation.

\section{Conclusion:}

Based on the results of this study it can be concluded that: The Dynamic Hip Screw (DHS) 
device is the implant of choice in stable intertrochanteric fractures and does not produce clinically important changes in proximal femur morphology. The neck-shaft angle is the most important parameter in the morphology of the proximal part of the femur and fixation of intertrochanteric fracture by DHS must preserve the normal angel after fixation to avoid valgus and varus mal-union. The Egyptian dimensions of proximal femur are nearly similar to the Western standard and the dimensions of the currently available DHS implant match the dimensions of Egyptian femora. Age and gender play an important role in changes in proximal femur morphology after fixation. Varus malunion is not accepted after fixation of intertrochanteric fractures by DHS. Restoration of normal proximal femur morphology give the best clinical results of DHS in fixation of intertrochanteric fractures.

\section{Conflicts of interest:}

No conflicts of interest declared.

\section{Authors' contributions:}

All authors had equal role in design, work, statistical analysis and manuscript writing.

\section{References}

1- SEYFETTINOGLU F., ERSAN O., KOVALAK E., DUYGUN F., OZSAR B. and ATES, Y.: Fixation of femoral neck fractures with three screws: Results and complications. Acta. Orthop. Traumatol. Turc., 45 (1): 6-13, 2011.

2- BHANDARI M., DEVEREAUX P.J., SWIONTKOWSKI M.F., TORNETTA P., OBREMSKEY W., KOVAL K.J., et al.: Internal fixation compared with arthroplasty for displaced fractures of the femoral neck. A meta-analysis. J. Bone Joint Surg. Am., Sep., 85-A (9): 1673-81, 2003.

3- JANZING H.M., HOUBEN B.J., BRANDT S.E., et al.: The Gotfried percutaneous compression plate versus the dynamic hip screw in the treatment of pertrochanteric hip fractures: Minimal invasive treatment reduces operative time and post-operative pain. J. Trauma, 52 (2): 293-8, 2002.

4- CHANG C.W., LAI K.A. and YANG C.Y.: Failure of compression hip screw: Analysis of the failure mechanism. J. Musculoskeletal. Research, 6; 2: 101-6, 2002.

5- LEUNG K.S., SO W.S., SHEN W.Y. and HUI P.W.: Gamma nails and dynamic hip screws for peritrochanteric fractures. A randomized prospective study in elderly patients. J. Bone Joint Surg., 74-B: 345-51, 1992.

6- BARRIOS C., WALDHEIM G., BROSTROM L.A., OLSSON E. and STARK A.: Walking ability after internal fixation of trochanteric hip fractures with Ender Nails or Sliding Screw Plate: A comparative study of gait. Clin. Orthop. Relat. Res., 294: 187-92, 1993.

7- SIMPSON A.H.R.W., VARTY K. and DODD C.A.F.: Sliding hip screws: Modes of failure. Injury, 20: 227-31, 1989.
8- BAUMGAERTNER M.R., CURTIN S.L., LINDSKG D.M. and KEGGI J.M.: The value of the tip-apex distance in predicting failure of fixation of peritrochanteric fracture fixation. J. Bone Joint. Surg., [A], 77-A: 1058-64, 1995.

9- HELSINKI: World Medical Association Declaration of Helsinki: Ethical principles for medical research involving human subjects. J.A.M.A., 310 (20): 2191-4, 2013.

10- HAJBAGHERY M.A. and ABBASINIA M.: Quality of Life of the Elderly after Hip Fracture Surgery: A CaseControl Study. Journal of Caring Sciences, 2 (1): 53-9, 2013.

11- HARRIS W.H.: Traumatic arthritis of the hip after dislocation and acetabular fractures: Treatment by mold arthroplasty. An end-result study using a new method of result evaluation. J. Bone Joint Surg. Am., 51 (4): 737$55,1969$.

12- PIRES R.E.S., PRATA E.F., GIBRAM A.V., et al.: Radiographic anatomy of the proximal femur: Correlation with the occurrence of fractures. Acta. Ortop. Bras., 20 (2): 79-83, 2012.

13- McDONALD J.H.: Students' $t$-test. Handbook of Biolological Statistics, sparky house publishing, Baltimore, Maryland, U.S.A. $3^{\text {rd }}$ ed., 121-30, 2014.

14- WOLFGANG G.L., BRYANT M.H. and O'NEILL J.P.: Treatment of intertrochanteric fractures of the femur using sliding screw plate fixation. Clin. Orthop., 163: 148-58, 1982.

15- LEUNG K.S., SO W.S., SHEN W.Y. and HUI P.W.: Gamma nails and dynamic hip screws for peritrochanteric fractures. J. Bone Joint. Surg. (Br.), 74-B: 345-51, 1992.

16- BORIANI S., De IURE F., BETTELLI G., et al.: The results of a multicenter Italian study on the use of the Gamma nail for the treatment of pertrochanteric and subtrochanteric fractures: A review of 1181 cases. Chirurgia Degli Organi De Movimento, 79 (2): 193-203, 1994.

17- BRIDLE S.H., PATEL A.D., BIRCHER M. and CALVERT P.T.: Fixation of intertrochanteric fractures of the femur: A randomized prospective comparison of the Gamma nail and the dynamic hip screw. J. Bone Joint Surg., (Br.), 73-B: 330-4, 1991.

18- GOFFIN J.M., PANKAJ P. and SIMPSON A.H.: The importance of lag screw position for the stabilization of trochanteric fractures with a sliding hip screw: A subjectspecific finite element study. J. Orthop. Res., 31 (4): 596600, 2013.

19- BAUMGAERTNER M.R., CURTIN S.L., LINDSKOG D.M. and KEGGI J.M.: The value of the tip-apex distance in predicting failure of fixation of peritrochanteric fractures of the hip. J. Bone Joint Surg. Am., 77 (7): 1058-64, 1955.

20- BAUMGAERTNER M.R. and SOLBERG B.D.: Awareness of tip-apex distance reduce failure of fixation of trochanteric fractures of the hip. J. Bone Joint Surg., (Br.), 79 (6): 969-71, 1997.

21- HOAGLUND F.T. and LOW W.D.: Anatomy of the femoral neck and head, with comparative data from Caucasians and Hongkong Chines. Clin. Orthop., 152: 10-6, 1980.

22- SAIKIA K.C., BHUYAN S.K. and RONGPHAR R.: Anthropometric study of the hip joint in Northeastern region population with computed tomography scan. Indian J. Orthop., 42: 260-6, 2008. 
23- CHAUHAN R., PAUL S. and DHAON B.K.: Anatomical parameters of North Indian Hip Joints: Cadaveric. study. J. Anat. Soc. India, 51: 39-42, 2002.

24- RAVICHANDRAN D., MUTHUKUMARAVAL N., JAIKUMER R., et al.: Proximal femoral geometry in indians and its clinical applications. J. Anat. Soc. India, 60 (1): 6-12, 2011.

25- HOFFMANN R. and HAAS N.P.: AO Principles of Frac- ture Management (Vol. 2), second expanded edn; Thieme Publication, 751-4, 1999.

26- DeLEE J.C.: Rockwood and Green's Fractures in Adults Vol. 2, $4^{\text {th }}$ ed. Philadelphia, Lippincott Raven, 1659-739, 1996.

27- MISHRA A.K., CHALISE P., SINGH R.P. and SHAH R.K.: The proximal femur a second look at rational of implant design. Nepal. Med. Coll. J., 11 (4): 278-80, 2009.

\section{تهمليل فشل تثبيت مسمار الوريك الديناميكى

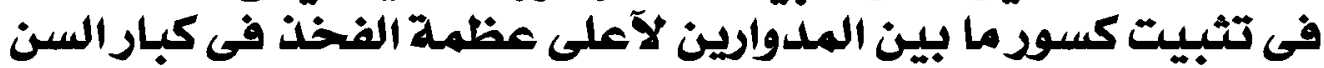

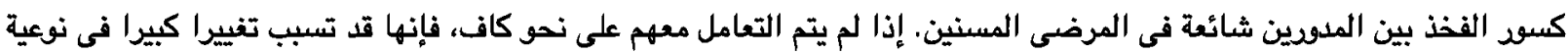

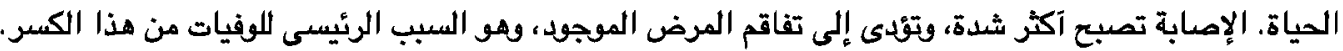

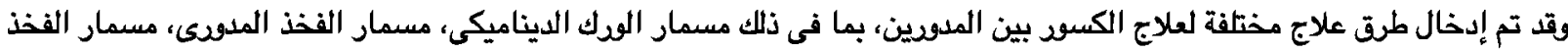

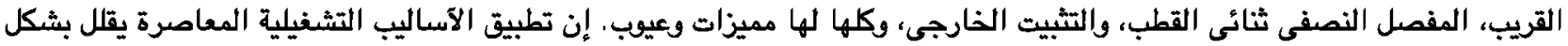
كبير من مخاطر الوفيات، بالمقارنة مع الطرق التمفي التحفية للعلاج.

وعلاوة على ذللك، تمكن الآساليب المعاصرة إلى نسب آقل من المضاعفات، وإلى نتائج وظيفية صالحة. وإن مسمار الورك الديناميكى بمثابة

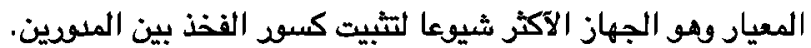

إن الهدف من العلاج الجراحى لمثل تلك الكسود هو التثييت القوى والثابت لآجزاء الكسر ويعتبر مسمار الورك الديناميكى هو الإختيار

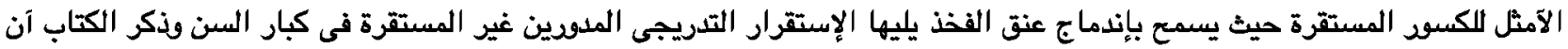

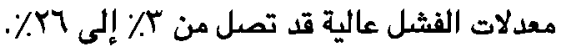

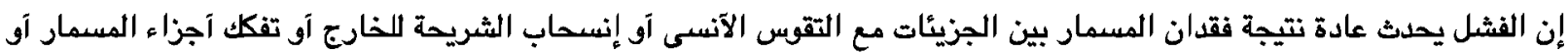

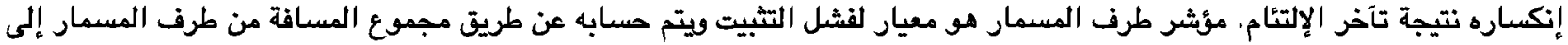

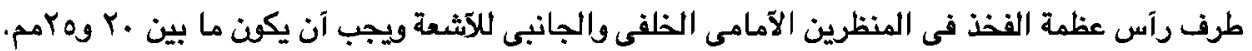

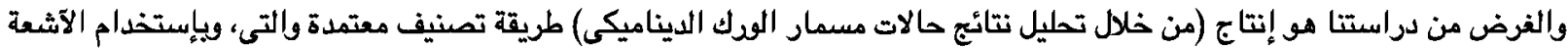
يمكن التبؤ بها على حد سواء بمضاعفات ما بعد الجراحة، وكذلك التدليل على آهمية هشاشة العظام فى علاج هذه الكات الكسود الصعبة. 